\title{
Research on the Economic History of Dali in the Late Ming Dynasty under the Background of Social Transformation
}

\author{
Zhu Zhu * \\ No. 5 Middle School, Huiyang District, Huizhou, 516211, China \\ *zeya.zhu@warwick.ac.uk
}

\begin{abstract}
The Ming dynasty was one of the most prosperous dynasties in ancient China and one of the most distinctive and important periods in the history of Chinese feudal society. The late Ming dynasty was an important turning point in social and economic development. In the context of social transformation, the development of commercial agriculture caused structural changes in the agricultural economy and rural society; the prosperity of regional commercial trade, the growth of merchant power and the formation of inter-regional market networks created a new stage in the development of regional commerce. This paper examines the economic development of the Dali region in the late Ming dynasty from a regional perspective against the backdrop of social transformations, taking into account the economic development of the region in the late Ming dynasty in terms of factor inputs and outputs of economic activities, foreign trade and commercial development, and finance and finance. The findings of this paper can provide a reference for deepening the study of regional economic history and promoting regional economic development.
\end{abstract}

Keywords: Social Transformation; Late Ming Dynasty; Dali Region; Economic History.

\section{Introduction}

The in-depth study of the characteristics of the socio-economic development of various peoples and regions and their interrelationships from a global historical perspective, and the elaboration of the diversity and unevenness of history and its dynamic development, gradually became an international academic trend [1]. The late Ming dynasty was the beginning of China's early. The late Ming Dynasty was the beginning of China's early modernization, when ancient Chinese society began its transition to a modern society. Yunnan belonged to one of the most dynamic frontier regions of China's economic development during the Ming dynasty; and for Yunnan, the Ming dynasty was undoubtedly one of the most notable and crucial periods in the history of Yunnan's economic development. The integration of the Dali region with the central government entered an important period in the late Ming dynasty, when many aspects of the region's politics, economy, culture and education were integrated into the national unity, and the entire economic development encompassed essentially all the elements of development under traditional economic conditions. The study of economic history not only provides an overall, structural and historical grasp of the economy and society, but also tests the authenticity and reliability of the reconstructed data [2]. By deepening the study of local economic history and exploring it horizontally in the context of social transformation, more experience can be accumulated for building new regional characteristics and advantages.

\section{The Economic Development of the Dali Region in the Late Ming Dynasty}

One of the longest ruling dynasties in Chinese history, the late Ming dynasty was characterized by uneven socio-economic development across the regions. Yunnan, situated in a mountainous and multi-ethnic province on the south-western frontier of China, was a semi-enclosed and barbaric land that historically had limited influence on the nation in political, economic and cultural terms. Under the central integrated development process, various new changes have continued to change the way in which the socio-economic development of the frontier regions has been carried out, and not only the productivity of the frontier ethnic areas has been developed to a greater extent [3]. Dali is located in the central western part of Yunnan Province, with a high topography in the north-west and a low topography in the south-east; a complex and diverse landscape with high mountains and valleys; and 
numerous lakes and basins, distributed in plumes and bands [4]. Dali has many unique advantages in terms of resources and their geographical mix, and its natural conditions are favorable for the survival and reproduction of human beings and for social and economic development.

The socio-economic and cultural development of the Dali region, like that of human society as a whole, underwent a process of development from the lower to the higher levels. During the Ming dynasty Dali continued to collide with the mainland in economic and cultural exchanges, improving the lives of local inhabitants, promoting local construction, and inheriting and promoting its own traditional ethnic culture as it continued to develop its frontiers [5]. In the late Ming dynasty the Dali region underwent significant changes in its agricultural economy, industry and handicrafts, commerce and commercial capital, foreign links and trade, money and finance, etc.

\section{Inputs and Outputs in Economic Activity in the Dali Region during the Late Ming Dynasty}

\subsection{In Terms of Economic Activity Inputs}

Labour force demographic inputs. Existing research suggests that the natural attributes of the gender structure of the population were influenced differently by different political, economic and cultural circumstances, and that they also exhibited certain social characteristics. A comprehensive review by scholars suggests that the proportion of minority populations in Yunnan in the mid- to lateMing period was closer to $30 \%-40 \%$. This would put the total population of Yunnan during the Wanli period at between 1.42 and 2.21 million, with an average of 1.81 million. The population changes in Yunnan and Dali during the late Ming dynasty were very similar, both showing an upward and then a downward trend [6]. Due to the lack of historical data, it is difficult to study the age structure of the population of the Dali region as a whole during this particular period. In the Wanli period, there would have been at least 353,333 people in the Dali region. The population of the Dali region would have been at least 353,333 during the Wanli period, in the age range of 16-59 years, which falls within the category of strong adult labor force. In this case, there would have been 332,767 strong adults in the Dali region during the Tianqi period. In the Chongzhen period, the number of people in the 16-59 age group would have remained at around 186,667, barring other significant factors [7].

Land input. In traditional Chinese society, "people, land and soil" were regarded as the basis of wealth. Population production and land development were the successive dynasties attached great importance to population production and land development in order to facilitate the administration of the corvée and the collection of taxes [8]. During the 60 years of the late Ming Dynasty, the rulers took various measures to cultivate the land in order to maintain a stable social order and the normal functioning of the state machinery. As a result of the large-scale cultivation campaign in the first and middle Ming dynasties, the amount of cultivated land in the Dali region was greatly increased.

Technical resource input. In the late Ming Dynasty, new varieties of maize, potatoes and sweet potatoes were widely introduced and spread throughout the region for their drought-tolerant and highyielding advantages in order to further increase food production and meet the needs of a growing population and the development of the commodity economy. Vegetables were grown in all seasons in the Dali region, with different varieties in different seasons, most of which were cycled once a year. In the late Ming Dynasty, the development of iron smelting in mining and smelting production created conditions for agricultural production [9]. Oxen ploughing techniques became popular and stable in the Dali region over time, and the use of fertilizers in the Dali region was dominated by the application of farmyard manure, with more attention paid to targeted fertilization techniques. Water was the lifeblood of agriculture and the court attached great importance to its construction, and the Dali region was even more aware of this. 


\subsection{In Terms of Economic Output}

Agricultural output. The development of society in the late Ming Dynasty brought about comprehensive changes in the economy and social structure. Inputs in terms of human and land resources were increasing, and the total and unit yields of grain in the Dali region increased significantly compared to previous generations. The unprecedented development of cash crop cultivation has led to a major restructuring of the agricultural crop structure and has caused structural changes in the agricultural economy. Dali had a long history of being the centre of economic development in the western region, and the level of its agricultural economy was largely representative of that of the western region as a whole. The fact that the level of agricultural economic development in the Dali region in the late Ming dynasty was generally high, close to the provincial average, but second to that of the east.

Industrial and handicraft output. Historical records show that the integration of mining in the Dali region into the overall development framework of the imperial dynasty was mainly the main reason for this was the demand for major minerals such as silver, copper, iron and gold. The Ming dynasty was a period of great development for the mining industry in the Dali region. The silver industry in Dali developed tremendously, with production and silver classes being among the highest in the province, making Dali the most important silver producer in Yunnan at the time. The development of the textile industry in Dali had a very small proportion of government-run production and was mainly self-sufficient and managed by the private sector. Local government initiatives to encourage the development of the textile industry in the Dali region [10]. The textile industry in the Dali region was mostly self-sufficient and privately-owned and self-managed, influenced by geographic features, location conditions and resource endowments.

\section{Commercial Trade and Finance in the Dali Region in the Late Ming Dynasty}

The Dali region's trade and openness to the outside world was once said to have originated in the Qin and Han dynasties, to have been born in the Tang and Song dynasties, and to have changed in the Ming and Qing dynasties. During the Ming period, the social and economic development of the Dali region progressed and prospered as a result of the gradual increase in investment in the development of cantonment, water conservancy and technological and cultural innovation. The emergence of a series of new factors injected new vitality into the development of foreign trade and provided a solid material basis for its development. In the late Ming dynasty, transport in the Dali region was further developed and improved based on the Yuan dynasty. There was a wide range of guards along the regional transport routes, and the post, fortress and sentry posts were connected, making the roads safe and smooth. Objectively, the circulation of goods was active, creating the conditions for the development of the regional commodity economy. The socio-economic development of the late Ming Dynasty, the expansion and improvement of external transport links, and the close political, economic and cultural exchanges and links with neighboring countries contributed to a certain extent to the continuous prosperity of foreign trade in the Dali region. During the late Ming Dynasty, trade between the Dali region and Laos, Thailand and Cambodia also developed to a certain extent, especially with the constant tributes from both sides. In the late Ming Dynasty, the trade between the Dali region and the Lao PDR, Thailand and Cambodia developed considerably, and the border market became an important part of foreign trade. The material basis for the development of the border trade was the development of the border area. By the late Ming Dynasty, the commercial economy of the Dali region was quite active, and many important cities of varying sizes, such as Dali, Heqing and Binchuan, had been formed. Commerce was mainly concentrated in these cities, which, like the mainland, were both political and commercial centres.

The late Ming dynasty saw a dramatic decline in the ruling power of the Ming dynasty. Class conflicts intensified as a result of the substantial increase in taxation and servitude efforts and the large-scale annexation of land by bureaucratic landowners. There were many types of taxes and serious taxation, but most of them were miscellaneous taxes and subject levies that were temporarily 
added in the later period. There were three main types of taxes: field tax, commercial tax and various types of corvée. The distribution of taxes was unreasonable, and the distinction between regional priorities and tax arrears was significant. In the late Ming Dynasty, the finance of the Dali region consisted mainly of field taxation, miscellaneous taxes and expenses. Field and miscellaneous taxes were the main sources of finance. During the late Ming dynasty, due to the influence of economic changes and social changes, the concept of consumption changed, the intensity of consumption increased, the orientation of consumption changed, and the differences in consumption expanded, resulting in a number of significant changes and new characteristics of consumption.

\section{Conclusion}

The Ming Dynasty was the late period of Chinese feudal society. The late Ming Dynasty was a period of comprehensive social and economic development, with profound changes in the economic structure, social structure and production relations. The changes in social and economic development during the late Ming period were mainly in the areas of agriculture, handicrafts, commerce and foreign trade. In addition, based on the political, economic and social development of the late Ming Dynasty, the economic and social development of the society was also in the process of change. In addition, a diverse mix of the old and the new came to the fore in the late Ming society, based on a number of new factors in the political, economic, social, ideological and cultural spheres. The integration of the Dali region in relation to the central government was at an important period in the late Ming dynasty. Many political, military, economic, cultural and educational aspects of the region were integrated into the larger national unity. The differentiated approach to rule based on local characteristics led to the economic development of the Dali region.

\section{References}

[1] Wu Zhi. A political economy analysis of socio-economic institutional change - A comparison of the sprouting and development of capitalism in Britain and the Ming Dynasty as an example[J]. Contemporary Economic Studies,2017(09):64-72.

[2] Hao Junliang, Wu Jiawang. Economic initiatives of the Ming dynasty in governing the border ethnic areas of Yunnan [J]. China Business (second half of the month), 2009(06):297-300.

[3] Shi Yadong. A brief discussion on the economic thought of national defense during the Ming Dynasty with Liu Ji, Zhang Juzheng and Xu Guangqi as examples[J]. Cang Sang,2009(03):21-22+25.

[4] Yang, Liu, Pengyuan. Examining the hindrance of eunuchs to economic development in the middle and late Ming dynasty from an economic perspective[J]. Journal of Economic Research,2011(23):292-293.

[5] Zhao Pingliu. The impact of the Ming Dynasty post system on the socio-economy of the southwest [J]. Journal of Guizhou University for Nationalities (Philosophy and Social Science Edition),2018(06):25108.

[6] Jiang Hai. Proceedings of the Symposium on the History of Modern Economic Development in China [J]. Studies in Chinese Economic History, 1996(01):160-162.

[7] Guo Zhixiang. A brief discussion of the status of merchants in ancient times [J]. Nanjing University Law Review, 1996(02):106-109.

[8] Long Denggao. The commodity economy, land system and the history of China's economic development: an interview with Professor Li Tiandi [J]. Studies in Chinese Economic History, 2000(01):145-149.

[9] Xu Hui, Zou Dexiu. A historical account of ecological environment and economic and social development in ancient China [J]. Ecological Economy, 2000(04):33-37.

[10] Ling Chen. An exploration of the interaction between the historical evolution of economic law and economic development [J]. Science and Technology Entrepreneurship Monthly,2021,34(06):28-32. 